\title{
Erratum
}

\section{Effects of Forest Type and Human Presence on Bonobo (Pan paniscus) Density in the Salonga National Park}

\author{
DOI: 10.1007/s10764-006-9020-9; International Journal of Primatology, \\ Vol. 27, No. 2, April 2006, pp. 603-634
}

\section{Gay E. Reinartz, ${ }^{1,4}$ Inogwabini Bila Isia, ${ }^{1,3}$ Mafuta Ngamankosi, ${ }^{2}$ and Lisalama Wema Wema ${ }^{3}$}

Published Online September 8, 2006

Please note the following corrections to the article as published:

1. Introduction

(a) In the original published article, the first sentence of the first paragraph should read: "Accurate information on population size, habitat characteristics and threats to survival is essential to assess population trends and to formulate responsive conservation plans for endangered species (Ratti and Garton, 1996)."

2. Results

(a) Nest-Site, Nest, and Bonobo Density: The Kruskal-Wallis values given in this section should be a $\mathrm{H}_{\text {adj }}$ values rather than just $\mathrm{H}$ values.

(b) Forest Sampling: The second sentence of the first paragraph should read: "Old secondary forests comprised $21 \%$ of the forest type sampled; however, the proportion may be overrepresented in our sample because we selected study sites based on their accessibility...

\footnotetext{
${ }^{1}$ Zoological Society of Milwaukee, 1421 N. Water Street, Milwaukee, Wisconsin.

${ }^{2}$ Institut Conglais pour la Conservation de la Nature (ICCN), 13 Avenue des Cliniques; Commune de la Gombe, Kinshasa I, DRC.

${ }^{3}$ Present affiliation: World Wildlife Fund, 6 Lodja Avenue, Quartier Socimat Commune, Gombe, Kinshasa I, DRC.

${ }^{4}$ To whom correspondence should be addressed; e-mail: gayr@zoosociety.org.
} 
(c) Bonobo Density and Forest Types: The second sentence of the first paragraph should read: "We designated the forest types with no bonobo nests as other forest types." The second sentence in the second paragraph is incomplete as published, and should read: "However, after excluding the area of other forest types, the forest types where we found no nest site or nest, there is no significant difference in the number of nest sites in these 3 forest types $(G=5.633$, d.f. $=2, P>0.05$, Table IV).”

\section{Discussion}

(a) The fifth sentence in the second paragraph should read: "The primary forest described for Wamba by Idani et al. (1994) and Kano and Mulavwa (1984) (or the dry forest; Hashimoto et al., 1998) potentially includes 6 forest types that we identified: the mixed mature forest of various understory composition (woody, Marantaceae, liana, and open understory) and the monodominant Gilbertiodendron forests (woody and open understory)."

(b) The fifth sentence in the fifth paragraph shoud read: "Several authors (Badrian and Malenky, 1984; Idani et al., 1994) hypothesized that the larger mean and modal daytime group size at Wamba versus Lomako is due primarily to the abundance and stability of food sources created by a balanced complex of diverse vegetation, including a greater proportion of terrestrial herbaceous vegetation."

(c) The third sentence of the sixth paragraph should read: "Though the sample size was extremely small, they also recorded a behavioral change in the formation of nest groups, i.e., the daytime parties split to form smaller nesting groups, in contrast to night-time party fusion noted previously by Fruth and Hohmann (1996)."

(d) The third sentence of the eleventh paragraph should read: "Despite what appeared to be suitable habitat, we did not place transects in Bekongo and Nkinki, which constitute $c a .20 \%$ of our reconnaissance effort, because they were essentially devoid of bonobo and large mammal signs, probably because of heavy hunting pressure."

\section{References}

The nineteenth reference should read: "Fruth, B., and Hohmann, G. (1996). Nest building behavior in the Great apes the great leap forward? In McGrew, W. C., Marchant, L. F., and Nishida, T. (eds.), Great Ape Societies, Cambridge University Press, Cambridge, pp. 225-240.”

5. Tables 


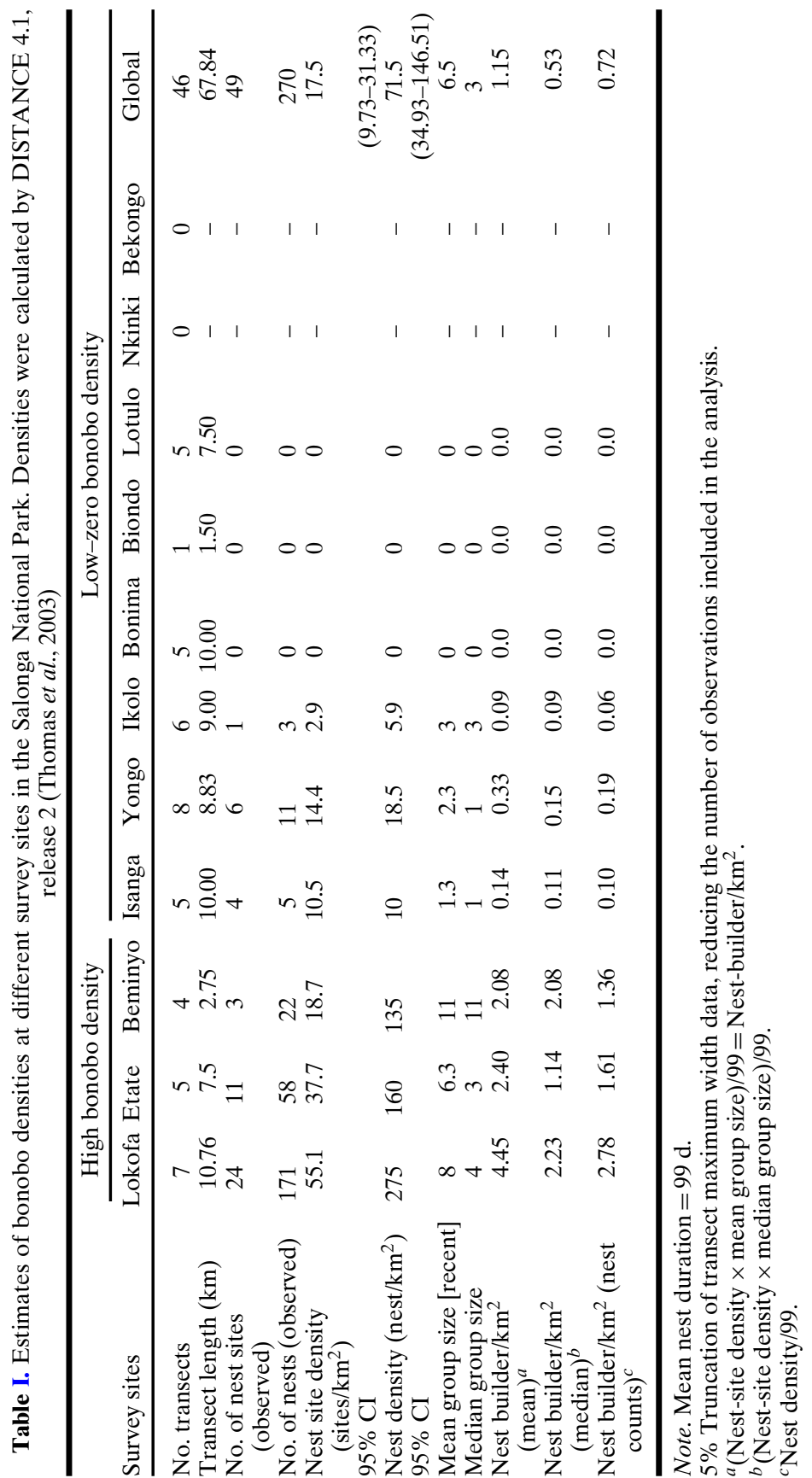

